\title{
ANALISIS TINGKAT KEPUASAN DI PUSKESMAS PAKUAN BARU KOTA JAMBI TAHUN 2020
}

\section{Analysis Of The Level Of Satisfaction At Puskesmas Pakuan Baru Jambi 2020}

\author{
Ririn Rosnardii ${ }^{1}$, Sugiarto ${ }^{2}$, Aidil Hafiz ${ }^{3}$ \\ Program Studi Ilmu Kesehatan Masyarakat STIKES Harapan Ibu Kota Jambi
}

\begin{abstract}
Abstrak
Kepuasan pasien pada salah satu penyedia layanan kesehatan di negara ASEAN tahun 2016 adalah sebesar $79 \%$ dan hal ini masih dibawah standar yang telah ditetapkan, dimana kepuasan pasien harus melebihi $80 \%$. Mutu pelayanan kesehatan di Indonesia sendiri masih rendah dibuktikan dengan peningkatan angka kesakitan di Indonesia khususnya di Indonesia bagian timur yang mencapai $40 \%$. Penelitian ini merupakan penelitian deskriptif kuantitatif dengan teknik pengambilan sampel secara accidental sampling dan teknik analisis menggunakan Importance Performance Analysis (IPA) dengan diagram kartesius. Tingkat kepuasan pasien berdasarkan seluruh dimensi (tangible, responsiveness, reliability, assurance dan empathy) di Puskesmas Pakuan Baru Kota Jambi Tahun 2020 adalah sebesar 98,6\%. Kepuasan pasien terhadap pelayanan di Puskesmas Pakuan Baru Kota Jambi berdasarkan seluruh dimensi kualitas pelayanan termasuk kedalam kategori sangat baik.
\end{abstract}

Kata Kunci: Kepuasan pasien, kualitas pelayanan

\begin{abstract}
Patient satisfaction at one of the health service providers in ASEAN countries in 2016 was $79 \%$ and this is still below the established standards, where patient satisfaction must exceed $80 \%$. The quality of health services in Indonesia itself is still low as evidenced by the increase in morbidity rates in Indonesia, especially in eastern Indonesia, which reached $40 \%$. This research is a quantitative descriptive study with accidental sampling technique and analysis technique using Importance Performance Analysis (IPA) with Cartesian diagram. The level of patient satisfaction based on all dimensions (tangible, responsiveness, reliability, assurance and empathy) at Puskesmas Pakuan Baru Jambi on 2020 was 98.6\%. Patient satisfaction with services at Puskesmas Pakuan Baru Jambi, based on all dimensions of service quality is included in the excellent category.
\end{abstract}

Keywords: Patient satisfaction, service quality

Korespondensi: Ririn Rosnardi

Email: ririnrosnardi.rr@gmail.com

\section{PENDAHULUAN}

Sistem pelayanan kesehatan di berbagi penjuru dunia memburuk, baik di negara berkembang ataupun di negara maju. Hal ini disebabkan oleh buruknya sistem dan fasilitas kesehatan yang disediakan oleh Pemerintah sehingga membuat petugas kesehatan sulit untuk memberikan pelayanan yang baik dan berkualitas kepada pasien sehingga menimbulkan rasa puas pada pasien. Kepuasan pasien adalah sesuatu yang penting, karena kepuasan pasien akan menentukan tingkat keberhasilan suatu penyelenggara pelayanan. Kepuasan pasien dipengaruhi oleh 5 (lima) dimensi kualitas pelayanan yaitu tangible/buktifisik, responsiveness/ketanggapan,

reliability/keandalan, assurance/jaminan dan empathy/empati. Berdasarkan hasil survey IKM di Puskesmas Pakuan Baru Kota Jambi pada tahun 2019 dapat dilihat 
bahwa jumlah indeks kepuasan masyarakat sebesar 3,2. Berdasarkan hasil survey IKM tersebut, Puskesmas Pakuan Baru Kota Jambi mendapatkan nilai $80,3 \%$ dengan kategori B (Baik) menurut Permenpan RB No. 14 Tahun 2017. Namun, walaupun hasil survey IKM di Puskesmas Pakuan Baru termasuk kedalam kategori baik tetapi masih ada beberapa masyarakat yang menyatakan bahwa pelayanan di

\section{METODE}

Penelitian ini menggunakan data sekunder Geografi, Demografi dan Indeks Kepuasan Masyarakat (IKM) Puskesmas Pakuan Baru Kota Jambi (2019), dengan rancangan penelitian deskriptif kuantitatif. Populasi penelitian ini berjumlah 7.728 orang dengan sampel sebanyak 95 orang. Instrumen pengumpulan data menggunakan kuesioner dengan teknik analisis data menggunakan IPA (Importance Performance Analysis).
Puskesmas Pakuan Baru belum memuaskan. Oleh karena itu, penelitian ini bertujuan untuk mengetahui gambaran tingkat kepuasan pasien di Puskesmas Pakuan Baru berdasarkan dimensi tangible, responsiveness, reliability, assurance dan empathy serta mengetahui prioritas perbaikan menggunakan diagram kartesius.

\section{HASIL PENELITIAN}

Persentase tingkat kesesuaian antara harapan dan kenyataan pada dimensi tangible $(100,6 \%)$, responsiveness $(102,4 \%)$, reliability $(93,5 \%)$, assurance $(98,7 \%)$ dan empathy $(98,3 \%)$. Tingkat kepuasan di Puskesmas Pakuan Baru Kota Jambi secara keseluruhan sebesar $(98,6 \%)$ dan termasuk kedalam kategori sangat baik.

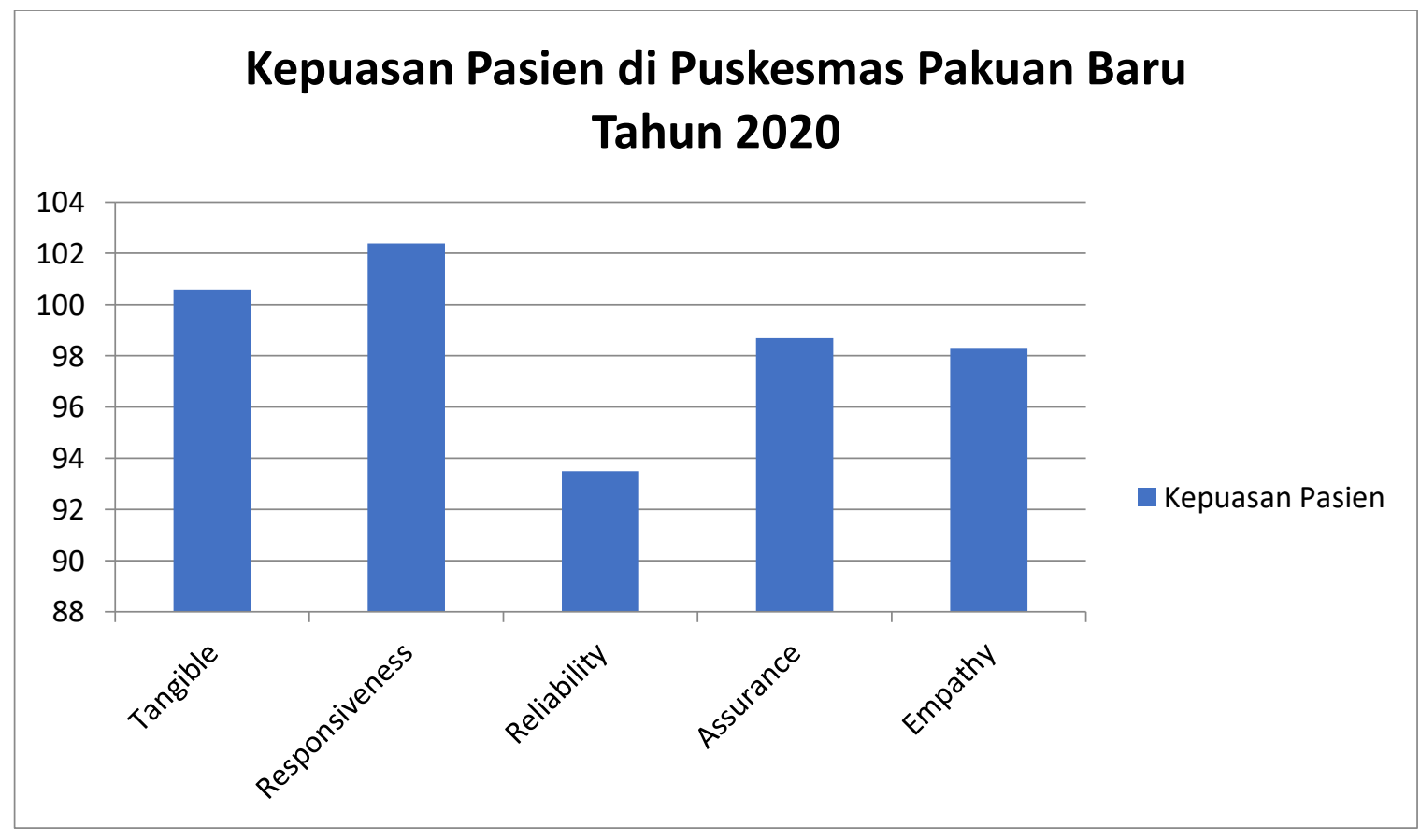

Gambar 1. Kepuasan Pasien Berdasarkan 5 (lima) Dimensi Kualitas Pelayanan di Puskesmas Pakuan Baru Kota Jambi Tahun 2020 


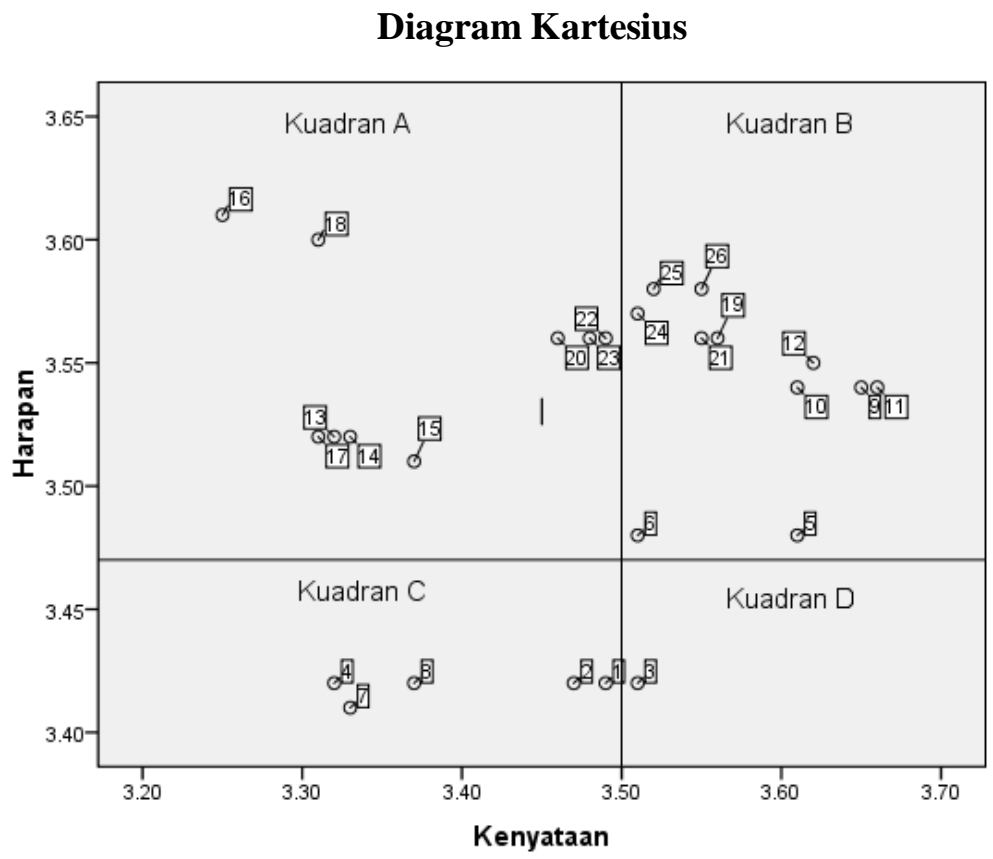

Gambar 2. Diagram Kartesius Prioritas Perbaikan Kualitas Pelayanan di Puskesmas Pakuan Baru Kota Jambi Tahun 2020

\section{PEMBAHASAN}

1. Gambaran Dimensi Mutu Kualitas Pelayanan terhadap Ketampakan Fisik (Tangible) di Puskesmas Pakuan Baru Kota Jambi

Berdasarkan hasil penelitian pada dimensi ketampakan fisik (tangible) di Puskesmas Pakuan Baru Kota Jambi didapatkan hasil sebesar 100,6\% dimana pasien sudah merasa sangat puas terhadap kualitas pelayanan Puskesmas Pakuan Baru pada dimensi tangible. Penelitian ini sejalan dengan penelitian yang dilakukan oleh Hizkia Jedia Budianto, dkk yang menyatakan bahwa variabel bentuk fisik (tangible) memiliki nilai pada uji t sebesar 0,013 atau $<0,05$, sehingga menunjukkan bahwa Ho ditolak dan $\mathrm{H} 1$ diterima yang berarti variabel bukti fisik (tangible) memiliki pengaruh terhadap kepuasan pelanggan.
2. Gambaran Dimensi Mutu Kualitas Pelayanan terhadap Ketanggapan (Responsiveness) di Puskesmas Pakuan Baru Kota Jambi

Berdasarkan hasil penelitian pada dimensi daya tanggap (responsiveness) di Puskesmas Pakuan Baru Kota Jambi didapatkan hasil sebesar 102,4\%. Hasil penelitian yang dilakukan oleh Happy Ayuningrum Putri Immas, dkk tentang pengaruh kualitas pelayanan terhadap kepuasan pasien di rumah sakit islam kota magelang yang menyatakan bahwa daya tanggap berpengaruh positif dan signifikan terhadap kepuasan pasien, dimana hasil uji korelasi yang didapatkan antara kedua variabel sebesar 0,927 yang berarti hubungan antara keduanya sangat kuat.

3. Gambaran Dimensi Mutu Kualitas Pelayanan terhadap Kehandalan 
(Reliability) di Puskesmas Pakuan Baru Kota Jambi

Berdasarkan hasil penelitian pada dimensi kehandalan (reliability) di Puskesmas Pakuan Baru Kota Jambi didapatkan hasil sebesar 93,5\%. Penelitian yang dilakukan oleh Happy Ayuningrum, dkk mengatakan bahwa dimensi kehandalan berpengaruh positif dan signifikan terhadap kepuasan pasien, yang mununjukkan hasil korelasi antara kehandalan dan kepuasan pasien adalah 0,881 yang berarti hubungan antara keduanya kuat.

4. Gambaran Dimensi Mutu Kualitas Pelayanan terhadap Jaminan (Assurance) di Puskesmas Pakuan Baru Kota Jambi

Berdasarkan hasil penelitian pada dimensi jaminan (assurance) di Puskesmas Pakuan Baru Kota Jambi didapatkan hasil sebesar 98,7\%. Hasil penelitian yang dilakukan oleh Jeiska T. Tulangow, dkk tentang analisis faktor-faktor yang berhubungan dengan kepuasan pasien di RSU, Manado yang menyatakan bahwa terdapat hubungan yang signifikan antara jaminan dan kepuasan pasien dengan nilai OR sebesar 11,445 yang berarti bahwa jaminan yang baik memiliki kepuasan pasien sebesar 11,445 kali lebih besar dibandingkan dengan jaminan yang tidak baik.

5. Gambaran Dimensi Mutu Kualitas Pelayanan terhadap Empati (Empathy) di Puskesmas Pakuan Baru Kota Jambi

Pada hasil penelitian yang peneliti lakukan di Puskesmas Pakuan Baru Kota Jambi terhadap dimensi empati (empathy) didapatkan hasil sebesar 98,3\% yang berarti pelayanan yang diberikan sudah sangat baik. Penelitian yang dilakukan oleh Hizkia Jedia Budianto, dkk tentang pengaruh kualitas layanan terhadap kepuasan pasien di Surabaya, menyatakan bahwa variabel empati memiliki pengaruh secara parsial terhadap kepuasan pasien. Dalam hal ini empati ditunjukkan dengan adanya perhatian lebih kepada pasien, sikap ramah dan peduli petugas yang diberikan kepada pasien.

6. Gambaran Tingkat Kepuasan Pasien di Puskesmas Pakuan Baru Kota Jambi

Berdasarkan hasil penelitian yang dilakukan oleh peneliti di Puskesmas Pakuan Baru Kota Jambi, didapatkan hasil tingkat kepuasan pasien terhadap 5 (lima) dimensi kualitas pelayanan adalah sebesar 98,6\%. Pada 5 (lima) dimensi tersebut, nilai terendah terdapat pada dimensi kehandalan (reliability) yaitu hanya sebesar 93,5\%. Secara keseluruhan tingkat kepuasan pasien di Puskesmas Pakuan Baru tergolong tinggi yaitu sebesar 98,6\% dan sudah termasuk kedalam kategori sangat baik (A) menurut Permenpan RB Nomor 14 Tahun 2017 tentang Pedoman Penyusunan Survei Kepuasan Masyarakat Unit Penyelenggara Pelayanan Publik.

\section{KESIMPULAN DAN SARAN}

Tingkat kepuasan pasien terhadap 5 (lima) dimensi kualitas pelayanan di Puskesmas Pakuan Baru Kota Jambi adalah sebesar 98,6\%. Berdasarkan analisis IPA (Importance performance Analysis) menggunakan diagram kartesius, didapatkan hasil bahwa Puskesmas Pakuan Baru Kota Jambi memiliki beberapa item yang menjadi prioritas utama dalam melakukan perbaikan untuk meningkatkan 
kualitas pelayanan di Puskesmas Pakuan Baru sehingga mampu menimbulkan rasa puas pada pasien. Item yang menjadi prioritas utama perbaikan yang terdapat pada Kuadran A adalah sebagai berikut: dokter selalu ada untuk memberikan pelayanan; dokter memberikan resep obat yang tepat untuk pasien; petugas selalu sabar dalam memberikan pelayanan; dokter memeriksa pasien sebelum membuat resep; petugas memberikan kesempatan kepada pasien untuk bertanya dan menyampaikan keluhan; petugas memberikan pelayanan sesuai dengan alur yang telah ditetapkan; dan petugas menerangkan tentang tindakan yang akan diberikan.

\section{DAFTAR PUSTAKA}

1. Ayuningrum. $\mathrm{H}$, dkk. Pengaruh Kualitas Pelayanan Terhadap Kepuasan Pasien di Rumah Sakit Islam Kota Magelang. Universitas Diponegoro.

2. Hidayatul, N, (2018). Meningkatkan Mutu Pelayanan Kesehatan dengan Penerapan Upaya Keselamatan Pasien di Puskesmas. Jurnal Administrasi Kesehatan Indonesia. Vol 6. No. 2, 150-151.

3. Isnindar, dkk, (2012). Analisis Tingkat Kepuasan Pasien Rawat Inap di Ruangan Penyakit Dalam terhadap Pelayanan di Instalasi Farmasi Rumah Sakit Periode Desember 2011 - Februari 2012.
Jurnal Manajemen dan Pelayanan Farmasi. Vol 3. No. 4, 240-241.

4. Jedia Budianto. H, dkk (2016). Pengaruh Kualitas Layanan Terhadap Kepuasan Pelanggan di Surabaya. Universitas Kristen Petra.

5. Jeiska T. Tulangow, dkk. (2015). Analisis Faktor-Faktor yang Berhubungan Dengan Kepuasan Pasien di Instalasi Rawat Inap F RSUP Prof. Dr. R. D. Kandou Manado. JIKMU. Vol 5. No. $2 a$.

6. Kamil, H. (2010). Tingkat Kepuasan Pasien Terhadap Mutu Pelayanan Kesehatan di RSUDZA Banda Aceh. Ideal Nursing Journal. Vol 3. No. 1. ISSN: 2087 2879.

7. Moenir, A.S, (2006). Manajemen Pelayanan Umum di Indonesia. Jakarta: Bumi Aksara.

8. Sugiyono, (2008). Metode Penelitian Kuantitatif, Kualitatif dan $R \& D$. Bandung: Alfabeta.

9. Tjiptono, F., \& Chandra, G. (2011). Service, Quality \& Satisfaction Edisi 3. Yogyakarta: Penerbit Andi.

10. Departemen Kesehatan RI, (2019). Profil Kesehatan Indonesia 2018. Nov 26, 2019. www.depkes.go.id

11. Departemen Kesehatan Provinsi Jambi, (2016). Profil Kesehatan Provinsi Jambi 2015. Nov 26, 2019. 